(2001). Accuracy of positron emission tomography for diagnosis of pulmonary nodules and mass lesions: a meta-analysis. JAMA. 285, p.914-24.

4. Tang, Kun , Wang et al. (2019). The value of ${ }^{18} \mathrm{~F}-\mathrm{FDG}$ PET/CT in the diagnosis of different size of solitary pulmonary nodules. Medicine. 98, 11 p-e14813 (doi: 10.1097/MD.0000000000014813).

5. Jess $P$, Seiersen $M$, Ovesen $H$ et

(2014). Has PET/CT a role in the characterization of indeterminate lung lesions on staging CT in colorectal cancer? A prospective study. Eur J Surg Oncol. 40, p.719-22.

6. Degirmenci $B$, Wilson $D$, Laymon $C M$ et al. (2008). Standardized uptake value based evaluations of solitary pulmonary nodules using F$18 \quad$ Fluoro-deoxyglucose-PET/computed tomography. Nucl Med Commun. 29, 7, p.614-22.

7. Van Gómez López 0 , García Vicente $A$, Honguero Martínez AF et al. (2015). ${ }^{18}$ F-FDG PET/CT in the assessment of pulmonary solitary nodules: comparison of different analysis methods and risk variables in the prediction of malignancy. Transl Lung Cancer Res. 4, 3, p.228-35.

8. Sang Mi Lee, So Won Oh, Ho-young Lee and Seok-Ki Kim. (2008). FDG PET/CT imaging findings in pulmonary metastases from colorectal cancer. Journal of Nuclear Medicine. 49, 1, p.112.

9. Bamba $Y$, Itabashi M, Kameoka S. (2011). Value of PET/CT imaging for diagnosing pulmonary metastasis of colorectal cancer. Hepatogastroenterology. 58, 112, p.1972-74.

\title{
TÌNH TRANG DINH DƯỡNG VÀ MộT Số YẾU TỐ LIÊN QUAN CỦA TRẺ DƯới 24 THÁNG TUỔI ĐIỀU TRI TẠI KHOA NHI BỆNH VIỆN E
}

\author{
Nguyễn Thị Ngọc Ánh ${ }^{1,2}$, Trương Văn Quý1,2, \\ Nguyễn Thị Diệu Thúy ${ }^{1}$, Nguyễn Quang Dũng ${ }^{1}$
}

\section{TÓM TẮT}

Nghiên cứu được thực hiện trên 121 cặp bà me có con từ 0 đến 24 tháng tuổi điều trị tại khoa Nhi bệnh viện $\mathrm{E}$. Nghiên cứu nhằm đánh giá tình trạng dinh dưỡng và mô tả một số yếu tố liên quan đển tình trạng suy dinh dưỡng (SDD) của trẻ em bằng phương pháp mô tả cắt ngang. Kết quả nghiên cứu cho thây tỷ lệ trẻ SDD thể nhẹ cân $(C N / T)$ là $7,4 \%$; suy dinh dưỡng thể thấp còi $(\mathrm{CC} / \mathrm{T})$ là $9,1 \%$; suy dinh dưỡng thể gâyy còm (CN/CC) là 9,9\%. Trẻ có me trên 35 tuổ có nguy cơ SDD thê gầy còm cao gấp 4,6 lần so với trẻ có mẹ dưới 35 tuổi $(p<0,05)$. Nguy cơ SDD thấp còi ở trẻ sinh ra trong gia đình có từ 2 con trở lên cao hơn nhóm còn lại với $\mathrm{OR}=7,4 ; p<0,05$. Trẻ có cân năng khi sinh $<2500 \mathrm{~g}$ có nguy cơ SDD gây còm và nguy cơ SDD thể nhẹ cân cao hơn trẻ có cân nặng khi sinh từ $2500 \mathrm{~g}$ trở lên với OR lần lượt là 12,3 và 10,4 với $p<0,05$. Chưa thấy mối liên quan có ý nghĩa thống kê giữa nghề nghiệp, kinh tế, trình độ hoc vấn, giới tính trẻ, tuổi của trẻ, cách thức sinh, kiển thức, và thực hành nuôi dương trẻ của bà mẹ với tình trạng suy dinh dưỡng theo các thể của trẻ.

Tư khóa: Trẻ em, suy dinh dưỡng, 0 - 24 tháng.

\section{SUMMARY \\ NUTRIONAL STATUS AND SOME FACTORS RELATED TO MALNUTRITION OF CHILDREN FROM 0 TO 24 MONTHS IN THE PEDIATRIC DERPARTMENT OF E HOSPITAL}

\footnotetext{
${ }^{1}$ Đại học Y Hà nội.

${ }^{2}$ Bềnh viện $E$

Chịu trách nhiệm chính: Nguyễn Thị Diệu Thúy

Email: nguyendieuthuyhmu@gmail.com

Ngày nhận bài: 9.8.2021

Ngày phản biên khoa hoc: 1.1.2021

Ngày duyệt bài: 12.10.2021
}

To asess the nutitional status and some factors related to malnutrition of children from 0 to 24 months in Pediatric department of E hospital. Method: A cross sectional descriptive study with 121 child - mother pairs. Results: The prevalence of manutrition of children from 0 to 24 months was $7,4 \%$ by WAZ; $9,1 \%$ by HAZ and $9,9 \%$ by WHZ. Children whose mothers were over 35 years old have a risk of underweight malnutrition 4.6 times higher than children whose mothers were under 35 years old $(p<0.05)$. The risk of stunting malnutrition in children born in families with 2 or more children is higher than the other group with $\mathrm{OR}=7.4 ; \mathrm{p}<0.05$. Children with birth weight $<2500 \mathrm{~g}$ had a higher risk of stunting malnutrition and underweight malnutrition than children with a birth weight $\geq 2500 \mathrm{~g}$ with Odd ratios of 12.3 and 10.4 respectively with $p<0.05$. There were no statistically significant relationships between occupation, economy, education level and childrearing practices of mothers with malnutrition.

Keywords: Children, malnutrition, 0-24 months

\section{I. ĐĂT VẤN ĐỀ}

Việt Nam trải qua thời kì chiến tranh kéo dài, kinh tế khó khăn với tỷ lệ trẻ suy dinh dưỡng rất cao vào khoảng $50 \%$ trẻ dưới 5 tuổi vào thập niên 80 , đến năm 2010 tỷ lệ suy dinh dưỡng thấp còi là $29,3 \%$, nhẹ cân $17,5 \%^{1}$. Theo báo cáo của tổ chức Alive \& Thrive (A\&T) về tình trạng dinh dưỡng trên 11 tỉnh thành cho thấy tỷ lệ thấp còi ở trẻ dưới 24 tháng tuổi là 9,5\% trong đó $5 \%$ là trẻ dưới 6 tháng tuổi và $15,3 \%$ trẻ từ 6 đến 23,9 tháng tuổi ${ }^{2}$. Ngày càng có nhiều bằng chứng cho thây suy dinh dưỡng trong giai đoạn phát triển quan trọng của con người - trước và trong quá trình mang thai và 
trong hai năm đâu đời của trẻ - đã "lập trình" cho khả năng của mỗi cá nhân trong việc điều tiết tăng trưởng và ảnh hưởng đến sự phát triển của não bộ. Do đó suy dinh dưỡng đâu đời có thể dẫn đến những tổn thương không hồi phục đối với sự phát triển của não, hệ miển dịch và tăng trưởng thể lực. Suy dinh dưỡng làm suy yếu hệ miễn dịch của trẻ, khiến trẻ có nguy cơ tử vong cao từ những bệnh thường gặp như viêm phổi, tiêu chảy hay sốt rét. Nghiên cứu này được thực hiện trên các bà mẹ có con dưới 24 tháng tuổi đến khám và điêu trị tại khoa Nhi bệnh viện E nhằm mục tiêu: Đánh giá tình trạng dinh dưỡng của tré dưới 24 tháng tuổi điều trị tại khoa Nhi- Bệnh viện E và nhận xét một số yếu tô liên quan.

\section{II. ĐỐI TƯỢNG VÀ PHƯƠNG PHÁP NGHIÊN CỨU}

Địa điểm nghiên cứu: khoa Nhi bệnh viện $\mathrm{E}$

2.1. Đối tượng và thời gian nghiên cứu

Tiêu chuấn lứa chon

- Cặp bà mẹ và trẻ dưới 24 tháng tuổi

- Điều trị nội trú tại khoa Nhi tại Bệnh viện E

Tiêu chuấn loại trư

- Trẻ đang trong tình trạng nặng, cấp cứu, hôn mê

- Mẹ trẻ rối loạn tâm thân, không có khả năng trả lời câu hỏi

Thời gian nghiên cứu: từ tháng 8/2020 đến tháng 4/2021

\subsection{Phương pháp}

Thiết kế nghiên cứu: Nghiên aưu mô tả cắt ngang.

Cơ mẫu và phương pháp chọn mẫu: Chọn mẫu thuận tiện lần lượt những bà mẹ có con trong độ tuổi từ 0-23 tháng tuổi đến khám và điều trị tại khoa Nhi - Bệnh viện $E$. Trên thực tế lấy được 121 mẫu trong thời gian thu thập số liệu nghiên cứu.

Phương pháp đánh giá: Sử dụng các số đo tháng tuổi, cân nặng, chiếu cao của trẻ và phân loại theo WHO 2006 với các chỉ số: WAZ (Z-score cân nặng theo tuổi), HAZ (Z-score chiều cao theo tuổi), WHZ (Z-score cân nặng theo chiều cao). Số liệu được nhập vào phần mêm Anthro của WHO năm 2006 sau đó được đánh giá theo phân loại của WHO so với chuẩn tăng trưởng WHO 2006 để đánh giá tình trạng dinh dưỡng.

Kết quả được xử lý bằng phần mềm SPSS 22.0

\section{KẾT QUẢ NGHIÊN CỨU}

\section{Bảng 3.1. Thông tin chung của trẻ}

\begin{tabular}{|c|c|c|}
\hline Chỉ số & Số lượng & Tỷ lệ (\%) \\
\hline Tuổi: Dưới 6 tháng & 19 & 15,7 \\
\hline $6-11$ tháng & 32 & 26,5 \\
\hline $12-23$ tháng & 70 & 57,8 \\
\hline Giới: Nam & 71 & 58,7 \\
\hline Nứ & 50 & 41,3 \\
\hline Tống & 121 & 100 \\
\hline
\end{tabular}

Nhânn xét: Tuối trung bình của trẻ là $12,7 \pm 5,9$ tháng, trẻ có tuối ít nhất là 1 tháng tuổi và cao nhất là 23 tháng tuổi. Trẻ trong độ tuổi từ 12 đến 23 tháng tuổi chiếm tỷ lệ 57,9\%.

Trẻ nam là 58,7\%. Tỷ lệ nam/nữ là 1,4:1

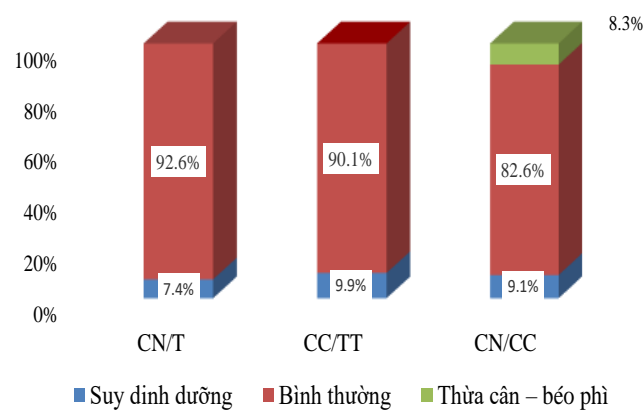

Biểu đồ 3.1. Tình trạng dinh dưỡng của trẻ Nhận xét: Suy dinh dưởng thể thấp còi chiếm tỷ lệ cáo nhất $9.9 \%$, tỷ lệ suy dinh dưỡng thể nhẹ cân chiếm $7,4 \%$. Tỷ lệ thừa cân - béo phì là $8,3 \%$.

Bảng 3.2. Cân nạng, chiều cao và chỉ số Z-Score trung binh cúa trẻ theo giới

\begin{tabular}{|c|c|c|c|}
\hline Chỉ số & Trẻ trai & Trẻ gái & p \\
\hline Cân nặng $(\mathrm{kg})$ & $9,2 \pm 1,7$ & $9,0 \pm 1,9$ & 0,31 \\
\hline Chiều cao $(\mathrm{cm})$ & $74,4 \pm 12,7$ & $72,3 \pm 13,3$ & 0,1 \\
\hline Z-score CN/T & $0,5 \pm 1,1$ & $-2,2 \pm 1,4$ & 0,28 \\
\hline Z-score CC/T & $-0,2 \pm 1,4$ & $-0,5 \pm 1,4$ & 0,51 \\
\hline Z-score CN/CC & $-0,4 \pm 1,5$ & $0,1 \pm 1,6$ & 0,12 \\
\hline
\end{tabular}

Nhận xét: Không thấy sự khác biệt có ý nghĩa thống kê giữa các chỉ số Z-score của trẻ theo giới tính với $p>0,05$.

Bảng 3.3. Liên quan giữa tuổi và số con hiện có của bà mẹ với tình trạng dinh dưỡng thể gây còm của trẻ

\begin{tabular}{|c|c|c|c|c|c|}
\hline \multirow{2}{*}{ Thông tin } & \multicolumn{2}{c|}{ SDD gây còm } & OR & \multirow{2}{*}{ (95\% } \\
\cline { 2 - 4 } & Có (n=11) & Không (n=111) & p \\
\hline \multirow{2}{*}{ Nhóm tuổi } & $\leq 35$ tuối & $6(6,1)$ & $93(93,9)$ & \multirow{2}{*}{$4,6(1,2-16,6)$} & 0 \\
\cline { 2 - 4 } & $>35$ tuối & $5(22,7)$ & $17(77,3)$ & \\
\hline Số con & 1 con & $0(0,0)$ & $45(100)$ & - & 0,001 \\
\hline & $\geq 2$ con & $11(14,5)$ & $65(85,5)$ & & \\
\hline
\end{tabular}


Nhận xét: Nguy cơ trẻ bị suy dinh dưỡng thể gây còm ở nhóm bà me >35 tuổi cao hơn so với nhóm bà me $\leq 35$ tuổi với $\mathrm{OR}=4,6(95 \% \mathrm{CI}=1,2-16,6)$. Nguy cơ SDD ở trẻ sinh ra trong gia đình có $\geq 2$ con cao hơn gia đình có 1 con; $p<0,05$.

Bảng 3.4. Liên quan giữa tiền sứ sản khoa của trẻ với tình trạng dỉnh dưỡng của trẻ

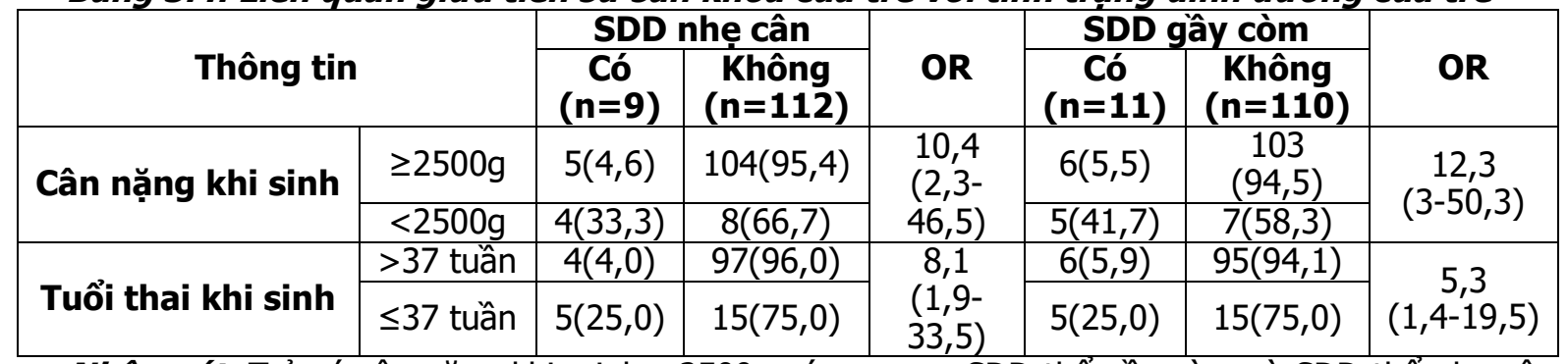

Nhận xét: Trẻ có cân nặng khi sinh <2500g có nguy cơ SDD thể gây còm và SDD thể nhẹ cân cao hớn trẻ có cân nặng khi sinh $\geq 2500 \mathrm{~g}$ với $\mathrm{OR}$ lần lượt là 12,3 và 10,4 với $p<0,05$. Trẻ sinh ra thiếu tháng nguy cơ SDD nhẹ cân và gầy còm cao hơn trẻ sinh ra đủ tháng với OR lần lượt là 8,1 và 5,3 với $p<0.05$.

\section{BÀN LUÂ̂N}

Tình trạng dinh dưỡng của trẻ dưới 24 tháng tuổi: Trong nghiên cứu của chúng tôi, trẻ SDD thể nhẹ cân chiếm tỷ lệ thấp nhất $7,4 \%$, sau đó đến SDD thể gầy còm $9,1 \%$ và cao nhất là SDD thể thấp còi $9,9 \%$. Kết quả này thấp hơn so với nghiên cứu của Ndemwa trên 380 cặp mẹ con được lấy ngẫu nhiên vào năm 2017 tại Kenya ${ }^{1}$ có tỷ lệ SDD thể nhe cân là $20,8 \%$, SDD thể thấp còi là $29,2 \%, \mathrm{SDD}$ thể gầy còm là $19 \%$. Tỷ lệ SDD thể nhẹ cân trong nghiên cứu này là $7,4 \%$ tương đồng với kết quả của Lương Tuấn Dũng năm 2012 có tỷ lệ trẻ < 24 tháng SDD nhẹ cân là $7,8 \%^{3}$. Tỷ lệ trẻ SDD thể thấp còi trong nghiên cứu của chúng tôi tương đương với tỷ lệ SDD thấp còi chung của trẻ dưới 24 tháng tuổi tại 15 quận huyện tại Hà Nội là 9,3\%. Tuy nhiên, kết quả này thấp hơn so với nghiên cứu của Nguyễn Thị Như Quỳnh ${ }^{4}$ năm 2021 là 22,5\%, nghiên cứu của Vũ Thị Trang ${ }^{5}$ tại Nam Định năm 2020 là $20,4 \%$. Tỷ lệ SDD thể gây còm theo nghiên cứu của chúng tôi tương đồng với nghiên cứu của Vũ Thị Nhung ${ }^{6}$ và Trần Thị Nhi tại Nam Định năm 2021 có $9,3 \%$ trẻ dưới 24 tháng tuổi SDD gầy còm nhưng cao hơn nghiên cứu của Lương Tuấn Dũng ${ }^{3}$ với $6,8 \%$ trẻ dưới 24 tháng tuổi SDD gầy còm ${ }^{9}$, nghiên cứu của Nguyễn Thị Như Quỳnh ${ }^{4}$ năm 2020 có $6,5 \%$ trẻ SDD gây còm ${ }^{3}$.

Một số yếu tố liên quan đến tình trạng SDD của trẻ dưới 24 tháng tuổi

Mốt số đặc điểm của mẹ: Kết quả nghiên cứu cho thây, trẻ có mẹ $>35$ tuổi có chiêu cao theo tuổi, cân nặng theo chiều cao thấp hơn so với trẻ có me $\leq 35$ tuổi, với $p<0,05$. Trẻ có mẹ $>35$ tuổi có nguy cơ SDD gâyy còm cao gấp 4,6 lần so với trẻ có mẹ $\leq 35$ tuổi $(95 \% \mathrm{CI}: 1,2$ -
$16,6 ; p=0,03)$. Lý giải vấn đề này chúng tôi cho rằng độ tuổi me trên 35 không còn là độ tuổi thích hợp để sinh con, trẻ sinh ra bởi các bà me cao tuổi dễ mắc các bệnh lý cấp tính hơn so với các bà me sinh con ở lứa tuổi được khuyến cáo. Kết quả nghiên cứu của chúng tồi cho thây có mối liên quan có ý nghĩa thống kê giữa số con trong gia đình với tình trang suy dinh dưỡng thể gày còm và thấp còi ở trẻ dưới 24 tháng tuổi. Cụ thể, gia đình có số con càng nhiều, nguy cơ trẻ bị suy dinh dưỡng thể thấp còi và gày còm càng cao. Tỷ lệ trẻ SDD gầy còm, thấp còi ở gia đình có từ 2 con trở lên đều là $14,5 \%$ trong khi tỷ lệ này ở gia đình có 1 con là $0 \%$ và $2,2 \%$. Trẻ sinh ra trong gia đình đông con có nguy cơ SDD thấp còi cao gấp 7,4 lần so với trẻ sinh ra trong gia đình ít con, với $p<0,05$. Nghiên cứu của Lương Tuấn Dũng ${ }^{3}$ (2012) tại Tuyên Quang cho thấy những gia đình có từ 2 con trở lên có nguy cơ SDD cao hơn những gia đình có dưới 2 con. Cụ thể tỷ lệ SDD thể nhẹ cân và thấp còi của trẻ ở gia đình có từ 2 con trở lên nguy cơ cao gấp 3,07 lần ( $\mathrm{OR}=3,07 ; 95 \% \mathrm{CI}: 1,28-7,38, \mathrm{p}<$ $0,01)$ và 2,26 lần $(\mathrm{OR}=2,26$; $95 \% \mathrm{CI}: 1,99$ $5,15, \mathrm{p}<0,05)$ so với trẻ ở gia đình có dưới 2 con. Nghiên cứu của Nguyễn Thị Thanh Thuấn tại Chiêm Hóa - Tuyên Quang năm 2010 cũng chỉ ra rằng nguy cơ SDD thể nhẹ cân và thấp còi của trẻ ở gia đình có từ 2 con trở lên cao gấp 1,54 lần (OR = 1,54; 95\%CI: 0,94-2,52, p > $0,05)$ và 1,98 lần $(\mathrm{OR}=1,98$; $95 \% \mathrm{CI}: 1,25$ $3,13, p<0,05)$. Chúng tôi cho rằng, những gia đình đông con dễ bị hạn chế về kinh tế hơn so với gia đình ít con, việc phân bổ không đầy đủ các nguồn lực của gia đình cho nhiều trẻ dẫn đến nguy cơ SDD ở những gia đình đông con. Ngoài ra, thời gian chăm sóc riêng cho từng trẻ ở 
những gia đình đông con sẽ ít hơn gia đình ít con.

Môt số đặc điểm của trẻ. Cân năng khi sinh thấp $(<2500 \mathrm{~g})$ là một vấn đề sức khỏe cộng đồng quan trọng ở nhiều nước đang phát triển, nguyên nhân chủ yếu do dinh dưỡng kém trước và trong quá trình mang thai. Nhiêu nghiên cứu đã cho thây trẻ có cân nặng khi sinh thấp có nguy cơ SDD cao hơn những trẻ có cân nặng khi sinh bình thường. Trong nghiên cứu của chúng tôi, trẻ sinh thiếu tháng có nguy cơ SDD gầy còm cao gấp 5,3 lần $(\mathrm{OR}=5,3 ; 95 \% \mathrm{CI}: 1,4-19,5$, $=0,02)$, SDD nhe cân cao gấp 8,1 lần ( $O R=$ $8,1 ; 95 \%$ CI: $1,9-33,5, \mathrm{p}<0,01)$ so với trẻ sinh đủ tháng. Nghiên cứu của Phạm Thị Diệp ${ }^{7}$ và Nguyễn Thị Thanh Luyến tại khoa Nhi - Bệnh viện Bắc Thăng Long năm 2019 cũng cho thây, trẻ sinh thiếu tháng có tỷ lệ SDD cao hơn trẻ sinh đủ tháng hoặc già tháng $(31,4 \%$ so với $15,3 \%), p<0,05$. Đây cũng là những kết quả quan trọng làm căn cứ để có những giải pháp dự phòng SDD ở trẻ nhỏ.

\section{KẾT LUÂN}

Suy dinh dưỡng là vấn đề sức khỏe toàn cầu, ảnh hưởng đến phát triển thể chất và tâm thần sau này. Nhận biết các yếu tố ảnh hưởng đến tình trạng suy dinh dưỡng ở trẻ nhỏ là căn cứ để đề ra các biện pháp dự phòng phù hợp.

\section{TÀI LIÊU THAM KHẢO}

1. Viện Dinh Dưỡng, UNICEF. Báo cáo tóm tắt tổng điều tra dinh dưỡng 2009-2010. Viện dinh dưỡng quốc gia: Nhà xuất bản Y học Hà Nội; 2011.

2. Thrive A. Báo cáo toàn văn thực hành nuồi dưỡng trẻ sơ sinh và trẻ nhỏ. 2012.

3. Lương Tuấn Dũng, Lê Thị Hương, Cao Hiên Trang và công sư. Tình trang dinh dưỡng và môt số yểu tố liển quan ở trẻ dưới 5 tuổi tại 2 xã Phúc Thịnh Xuân Quang, huyện Chiêm Hóa, tỉnh Tuyên Quang năm 2012. Tạp chí Y học thực thành. 2013;12(899):21 - 24.

4. Nguyễn Thi Như Quỳnh. Tình trang dinh dưỡng và một số yểu tố liên quan ở trẻ dưới 24 tháng tuổi đến khám tại trung tâm kiểm soát bệnh tật tỉnh Bắc Giang năm 2020. Luận văn Thạc sĩ Y học, Trường đại học Y Hà Nôii; 2021.

5. Vũ Thị Trang, Lê Thị Thu Hà, Nguyễn Trọng Hưng. Tình trạng suy dinh dưỡng thấp còi của tré 6 - 23 tháng tuổi tai xã Tân Thịnh, huyên Nam Trực, tỉnh Nam Định, 2020. Tạp chí Khoa học Nghiến cứu Sức khỏe và Phát triển. 2021;5(3):94 - 101.

6. Vũ Thị Nhung, Trân Thi Nhị. Tình trạng dinh dưỡng và một số yếu tố liên quan đến suy dinh dưỡng thể nhe cân của trẻ từ 0 - 24 tháng tai xã Vính Hào, huyền Vụ Bản tỉnh Nam Định năm 2021. Tap chí Y học Việt Nam. 2021;1(504):142 - 146.

7. Pham Thị Diệ̣̂, Nguyến Thi Thanh Luyến. Tình trạng dinh dưỡng va một số yếu tố liên quan ở trẻ từ 6 - 24 tháng tuổi tai Bệnh viện Bắc Thăng Long năm 2019. Tạp chí Ỳ học dự phòng. 2020;30(8):29 - 34

\title{
SỬ DUUNG MÁNG HƯớNG DẪN PHẪU THUÂT CẤY GHÉP IMPLANT SỚM LÀNH THƯƠ'NG MÔ MỀM TRÊN BẾNH NHÂN MẤT RĂNG TỪNG PHẦN VÙNG RĂNG TRƯỚC
}

\author{
Nguyễn Cao Thắng ${ }^{1}$, Trần Cao Bính ${ }^{2}$, Đàm Văn Việt ${ }^{2}$, \\ Đinh Diệu Hồng ${ }^{3}$, Trần Thị Mỹ Hạnh ${ }^{1}$
}

\section{TÓM TẮT}

Mục tiêu quan trọng để cấy ghép implant thành công là vị trí implant lý tưởng chính xác theo 3 chiều trong xương hàm, tồn tại lâu dài, đảm bảo được chự́c năng và thẩm mỹ. Việc sử dụng máng hướng dẫn phẫu thuật (MHDPT) trong cấy ghép implant được cho là mang lại nhiều lợi ích. Mục tiêu: Mô tả kết quả cấy ghép implant sớm lành thương mô mềm có ghép xương có sử dụng máng hướng dẫn phẫu thuât trên bệnh nhân mất răng từng phân vùng răng trước. Đối

${ }^{1}$ Viện Đào tạo Răng hàm mặt, Trường Đại học Y Hà Nội ${ }^{2}$ Bềnh viện Răng hàm mặt Trung ương Hà Nội

${ }^{3}$ Trường Đại hoc Y Dược - Đại học Quốc Gia Hà Nôi

Chịu trách nhiếm chính: Nguyễn Cao Thắng

Email: nctdentist@yahoo.com

Ngày nhận bài: 10.8.2021

Ngày phản biên khoa hoc: 5.10 .2021

Ngày duyệt bài: 13.10.2021 tượng và phương pháp nghiên cứu: Nghiên cứu can thiệp lâm sàng, so sánh độ lệch vị trí implant trước (theo kế hoach) - sau (thức tế điều tri). Đối tượng nghiên cứu là bệnh nhân từ 18 tuổi trở lên bị mất răng từng phân vừng răng trước được cấy ghép implant sử dưng máng hướng dấn phẫu thuật có ghép xương sau thời điểm nhổ răng $4-8$ tuần. Kết quả: Implant được sử dụng cấy ghép ở vùng mất răng phía có chiều dài từ $10 \mathrm{~mm}$ đến $14 \mathrm{~mm}$, chủ yếu là $12 \mathrm{~mm}$; có đường kính chủ yễu là $3,6 \mathrm{~mm}$ và $4,0 \mathrm{~mm}$. Lực vặn implant tối đa khi cấy ghép implant sớm lành thương mô mềm tại vùng mất răng phía trước hàm trên và hàm dưới trung bình là $58,03 \pm 9,095 \mathrm{~N} / \mathrm{cm}$ với các giá trị từ $45 \mathrm{~N} / \mathrm{cm}$ đến $80 \mathrm{~N} / \mathrm{cm}$. Khi thực hiện câyy ghép implant sớm lành thương mô mềm vùng rằng trước có sử dụng máng hướng dấn phẩu thuật, vị trí implant thực tế so với implant kế hoạch có độ lệch góc là 7,79 $\pm 4,79$, độ lệch vị trí platform là $1,82 \pm 1,29$, đô lệch vị trí chóp implant là $2,42 \pm 1,35$. Sư khác biêt độ lệch không có sự khác biệt giữa các vị tría mất răng hàm 